\title{
Characteristics of dissolved organic matter in forest soils: influence of different plant covering
}

\author{
${ }^{1}$ M.H. JIANG, ${ }^{2}$ X.F. ZHONG \& ${ }^{3}$ L.M. YANG \\ ${ }^{1}$ College of Geographical Science, Fujian Normal University, Fuzhou, 350007, China \\ ${ }^{2}$ Department of Geographical Science, Minjiang University, Fuzhou, 350108, China \\ ${ }^{3}$ College of Geographical Science, Fujian Normal University, Fuzhou, 350007, China
}

KEYWORD: forest soil; dissolved organic matter; chemical analyses; spectroscopy

ABSTRACT: To investigate the influence of different plant covering on dissolved organic matter (DOM) in forest soils, the DOM characteristics of soil sample in $P$. massoniana plantation forest and mixed conifer-broadleaf forest of $P$. massoniana and $C$. carlesii were researched by using chemical and spectroscopic methods, including total organic carbon (TOC), total nitrogen (TN), C/N ratios, dissolved organic carbon (DOC) and dissolved organic nitrogen (DON), together with aromaticity index (AIX) and humification index (HIX). Results showed that TOC, TN and C/N ratios were much higher in soils of PC than P, together with the level of DOC and DON, and the spectroscopic characteristics of DOM including AIX and HIX. It's suggested that different plant covering in forest have great influences on soil DOM characteristics. DOM concentrations in mixed forest of P. massoniana and $C$. carlesii were much higher than pure conifer forest of $C$. carlesii. Thus, mixed coniferbroadleaf forest was more suitable choice for ecological restoration and reconstruction in southeast China.

\section{INTRODUCTION}

Dissolved organic matter (DOM) has an important role in many chemical and biological processes occurring in soils, which include mobilization and transport of colloids, nutrients, metals and pollutants, and microbial growth (Kaiser \& Kalbitz, 2012). Kaiser et al. (2002) pointed out that the DOM in forest soils is constituted by a mixture of low-molecular weight and high-molecular weight compounds those are variously soluble and decomposable, which are mainly affected by litter decomposition and desorption from soil solid phases. The dominant source of DOM in forest soils is plant litter, while the composition of plant litter can be greatly influenced by vegetation type (Traversa et al., 2008). So tree species composition may affect the characteristics of DOM.

Pinus massoniana and Castanopsis carlesii are dominant coniferous and broadleaf trees in the southeast China. They often form pure plantation or mixed conifer-broadleaf forest, with significant difference in DOM composition (Feng et al., 2014). In the present study, the characteristics of DOM of cylindrical soil sample in $P$. massoniana plantation forest and mixed forest of $P$. massoniana and C. carlesii were studied by the chemical and spectroscopic methods, including total organic carbon (TOC), total nitrogen (TN), C/N ratios, dissolved organic carbon (DOC) and dissolved organic nitrogen (DON), together with aromaticity index (AIX) and humification index (HIX). Results of the study will provide useful information on the influence of different plant covering on the characteristics of DOM in forest soils, and provide a theoretical basis for ecological restoration and reconstruction in southeast China.

\section{MATERIALS AND METHODS}

\section{Site description}

The site of the present study is located in Shouning city, Fujian province, China $\left(27^{\circ} 31^{\prime} \mathrm{N}, 119^{\circ} 37^{\prime}\right.$ E). The average elevation is $890 \mathrm{~m}$ above the sea level, with the slope of $28-41^{\circ}$. The area is characterized by a subtropical marine monsoon climate, with average annual temperature of $14.9{ }^{\circ} \mathrm{C}$, the 
average annual rainfall of $898 \mathrm{~mm}$, annual evaporation capacity of $1400 \mathrm{~mm}$, and the relative humidity of $89 \%$.

The P. massoniana plantation (P) and mixed forest of $P$. massoniana and $C$. carlesii (PC) were established in 1976. The coverage of understory vegetation is about $90 \%$, with less bush and rich herbaceous layer. The soil characteristics are classified as red soil and quite homogeneous.

\section{Sample preparation}

Three cylindrical soil samples were collected randomly at selected sites in each forest type, with six different depths: 0-10 cm, 10-20 cm, 20-30 cm, 30-40 cm, 40-50 cm and 50-60 cm in July 2013. Part of composite soil samples were sieved $(<2 \mathrm{~mm})$ for DOM extraction, and another soils were air dried and sieved $(<2 \mathrm{~mm})$ for total organic carbon (TOC) and total nitrogen $(\mathrm{TN})$ analysis. Chemical and spectroscopic analyses

Basic soil properties like TOC and TN were performed according to standard methods (Lu, 1999). DOM were isolation as Traversa et al. (2008), aliquots of $10 \mathrm{~g}$ of each air-dried litter or soil sample were suspended in $100 \mathrm{ml}$ of $4 \mathrm{mM} \mathrm{CaCl}_{2}$ solution, and mechanically shaken for $15 \mathrm{~min}$. The suspensions were then centrifuged at $6000 \mathrm{rpm}$ for $15 \mathrm{~min}$, and filtered sequentially through Whatman filters with decreasing particle size retention, in the order: 11, 2.5, 1.2 and $0.45 \mathrm{~mm}$. All DOM samples were stored in the dark before analysis.

Then DOC and DON in DOM solutions were measured follow Höll et al. (2009), using an organic carbon analyzer (TOC-VCPH, Shimadzu, Kyoto, Japan) and an continuous stream dynamic analyzer (San++, Skalar, Breda, Netherlands), respectively. Each sample was analyzed three times, and the mean value was calculated. The variances of duplicate measurements were less than 5\%.

Spectroscopic analyses was taken at $254 \mathrm{~nm}$ by recording molar absorptivity on a UV-Vis spectrophotometer (UV-1200, Mapada, Shanghai, China). While Fluorescence spectra were recorded using a fluorescence spectrophotometer (F7000, Hitachi, Tokyo, Japan). And the AIX and HIX were calculated as $\mathrm{AIX}=(\mathrm{UV} 254 / \mathrm{DOC}) \times 100$ and $\mathrm{HIX}=$ the ratio between the area in the upper quarter $(435-480 \mathrm{~nm})$ and the area in the lower quarter $(300-345 \mathrm{~nm})$ of the emission spectra (Akagi et al., 2007).

\section{Data analysis}

Data were presented means $\pm \operatorname{SE}(n=5)$. Two-way analysis of variance was done on all the data to confirm the variability of data and validity of results using SPSS 15.0 software (SPSS, Inc., USA). Pearson correlation analysis was done to test the relationship between each chemical parameters and soil depth. Duncan's multiple range tests were performed to determine the significant difference between treatments at 0.05 probability.

\section{RESULTS}

\section{Soil properties}

TOC and TN of bulk soil samples were listed in Table 1. TOC and TN concentrations were greatest in the top layer, and decreased with soil depths, with TOC in 0-10 cm were 4.20 and 4.07 times higher than 50-60 cm in P and PC, and TN in 0-10 cm were 2.67 and 2.54 time than $50-60 \mathrm{~cm}$ in $\mathrm{P}$ and PC, respectively. Besides, TOC and TN in soils of PC were higher than P, with TOC in PC 1.271.35 folds higher than $\mathrm{P}$ and $\mathrm{TN}$ in $\mathrm{PC} 1.10-1.17$ folds higher than $\mathrm{P}$. Thereby resulted that $\mathrm{C} / \mathrm{N}$ ratios in soils of PC were folds 1.15-1.20 folds higher than $\mathrm{P}$ (Table 2). The $\mathrm{pH}$ in soils of PC were lower than $\mathrm{P}$, as the consequence of higher level of nutrients in soils of PC. 
Table 1. TOC and TN of bulk soil samples.

\begin{tabular}{|c|c|c|c|c|}
\hline \multirow[t]{2}{*}{ Depth $(\mathrm{cm})$} & \multicolumn{2}{|c|}{$\mathrm{TOC}\left(\mathrm{g} \mathrm{kg}^{-1}\right)$} & \multicolumn{2}{|c|}{$\mathrm{TN}\left(\mathrm{g} \mathrm{kg}^{-1}\right)$} \\
\hline & $\mathrm{P}$ & $\mathrm{PC}$ & $\mathrm{P}$ & $\mathrm{PC}$ \\
\hline $0-10$ & 115.72 & 147.32 & 9.31 & 10.12 \\
\hline $10-20$ & 58.13 & 78.65 & 5.24 & 5.97 \\
\hline $20-30$ & 49.64 & 65.43 & 4.71 & 5.18 \\
\hline $30-40$ & 44.67 & 58.54 & 4.62 & 5.17 \\
\hline $40-50$ & 32.43 & 43.78 & & $3.52 \quad 4.12$ \\
\hline $50-60$ & 27.54 & 36.21 & 3.49 & $9 \quad 3.99$ \\
\hline
\end{tabular}

P: pure $P$. massoniana forest; PC: mixed conifer-broadleaf forest of $P$. massoniana and $C$. carlesii.

Table 2. Selected properties of bulk soil samples.

\begin{tabular}{lccccc}
\hline Depth (cm) & \multicolumn{2}{l}{$\mathrm{pH}$} & \multicolumn{3}{l}{$\mathrm{C} / \mathrm{N}$ ratio } \\
\cline { 2 - 3 } \cline { 5 - 6 } & & & & \\
\cline { 3 - 4 } & & $\mathrm{PC}$ & & $\mathrm{P}$ & $\mathrm{PC}$ \\
\hline $0-10$ & 5.63 & 5.11 & & 12.43 & 14.56 \\
$10-20$ & 5.70 & 5.24 & & 11.09 & 13.17 \\
$20-30$ & 5.75 & 5.32 & & 10.54 & 12.64 \\
$30-40$ & 5.81 & 5.39 & & 9.67 & 11.32 \\
$40-50$ & 5.98 & 5.38 & & 9.21 & 10.63 \\
$50-60$ & 5.92 & 5.27 & & 7.89 & 9.08 \\
& & & & & \\
\hline
\end{tabular}

P: pure P. massoniana forest; PC: mixed conifer-broadleaf forest of P. massoniana and C. carlesii. DOM

As expected, DOC concentrations were greatest in the top layer, and also decreased with soil depths (Figure 1A). The DOC concentrations in $0-10 \mathrm{~cm}$ were 3.42 and 3.46 folds higher than $50-60 \mathrm{~cm}$ in $\mathrm{P}$ and PC, respectively. Similar trends were found in DON, with concentrations in $0-10 \mathrm{~cm}$ were 2.75 and 2.50 folds higher than $50-60 \mathrm{~cm}$ in $\mathrm{P}$ and $\mathrm{PC}$ (Figure 1B).

DOC in soils of PC were significantly higher than $P(P<0.05)$, while DON in $0-10 \mathrm{~cm}$ and $20-30 \mathrm{~cm}$ in soils of $\mathrm{PC}$ were also significantly higher than $\mathrm{P}(\mathrm{P}<0.05)$.

\section{Spectroscopic analyses}

The level of AIX in soils of PC were significantly higher than $\mathrm{P}(\mathrm{P}<0.05)$, and decreased at progressively greater depths (Figure 2A). The level of HIX show the same trends with AIX, higher level of HIX was found in the soil of PC (Figure 2B). In particular, the level of AIX and HIX in all layers of PC were average $18.33 \%$ and $49.16 \%$ higher than P. 

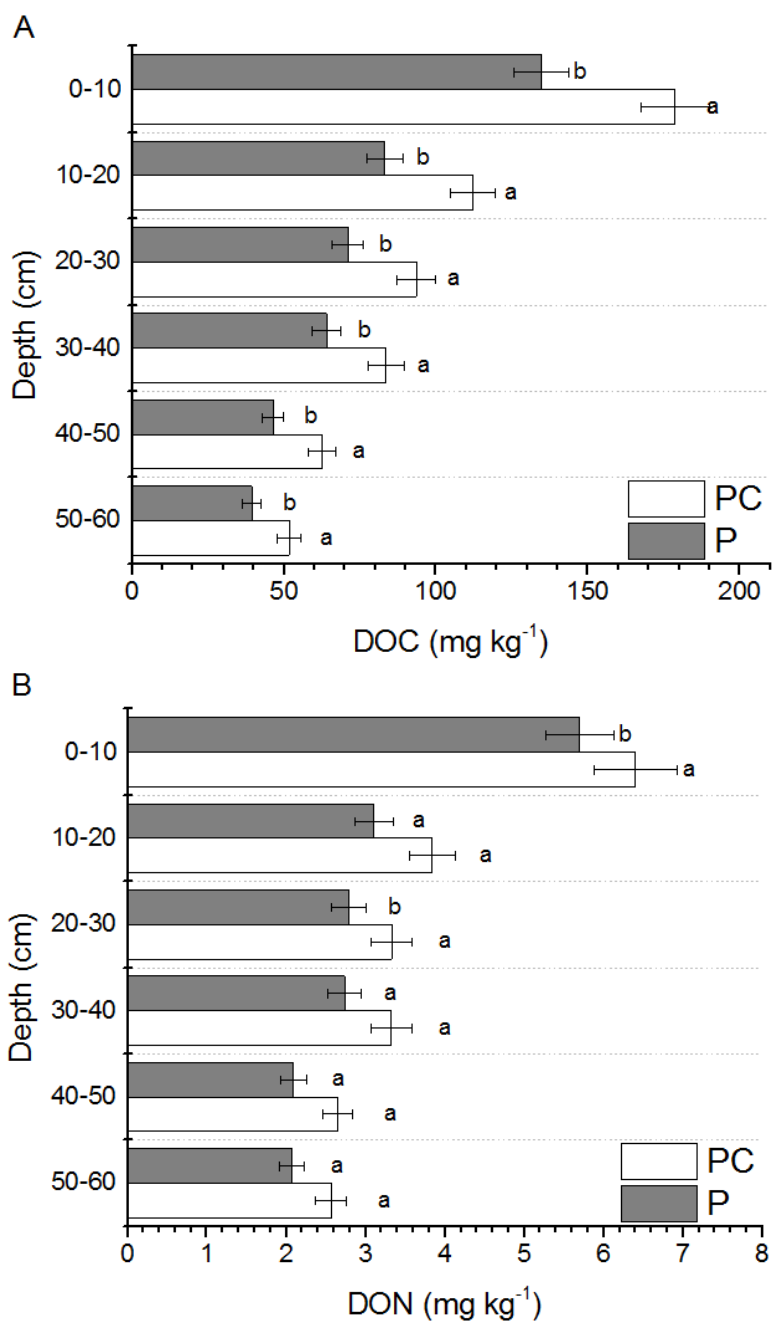

Figure 1. Contents of dissolved soil organic carbon and dissolved organic nitrogen at the two forest types (mean $\pm \mathrm{SE}, \mathrm{n}=5$ ). Different letters indicate significant differences between the two sites for the same soil layer $(\mathrm{P}<0.05)$. $\mathrm{P}$ : pure $P$. massoniana forest; PC: mixed conifer-broadleaf forest of $P$. massoniana and C. carlesii.

\section{DISCUSSION}

DOM is mainly from recent litter and humus decomposition, together with root exudates and soil microbial communities (Batlle-Aguilar et al., 2012). Though many studies have focused on the dynamics of DOM in forest ecosystems in recent years, there is a lack of knowledge concerning the effect of different forest plant covering on the amount and quality of DOM. In the present study, the characteristics of DOM of soil sample in $P$. massoniana plantation forest and mixed forest of $P$. massoniana and $C$. carlesii were researched by using chemical and spectroscopic methods.

The bulk analysis of forest soil with different plant covering provide basic information for further DOM analysis. Results showed those TOC, TN and $\mathrm{C} / \mathrm{N}$ ratios in soils of $\mathrm{PC}$ were higher than $\mathrm{P}$, and decreased at progressively greater depths. The $\mathrm{pH}$ soil in soils of PC were lower than $\mathrm{P}$, as the consequence of higher level of nutrients in soils of mixed conifer-broadleaf forest. These differences appeared to affect the translocation and properties of DOM through the corresponding underlying soil profile (Lyon et al., 2014).

Besides, the main object of the present study was to investigate the influence of different plant covering on the characteristics of dissolved organic matter in forest soils. The level of DOC in soils of PC were significantly higher than $\mathrm{P}(\mathrm{P}<0.05)$, while the level of DON in $0-10 \mathrm{~cm}$ and $20-30 \mathrm{~cm}$ in soils of PC were also significantly higher than $\mathrm{P}(\mathrm{P}<0.05)$. DOC and DON are the major components of DOM (Inamdar et al., 2012), these results suggested that DOM in soils of PC are richer than P, 
which may be mainly influenced by plant covering. Previous studies also demonstrated that DOM in mixed conifer-broadleaf forest was much higher than pure conifer forest (Laganiere et al., 2014).
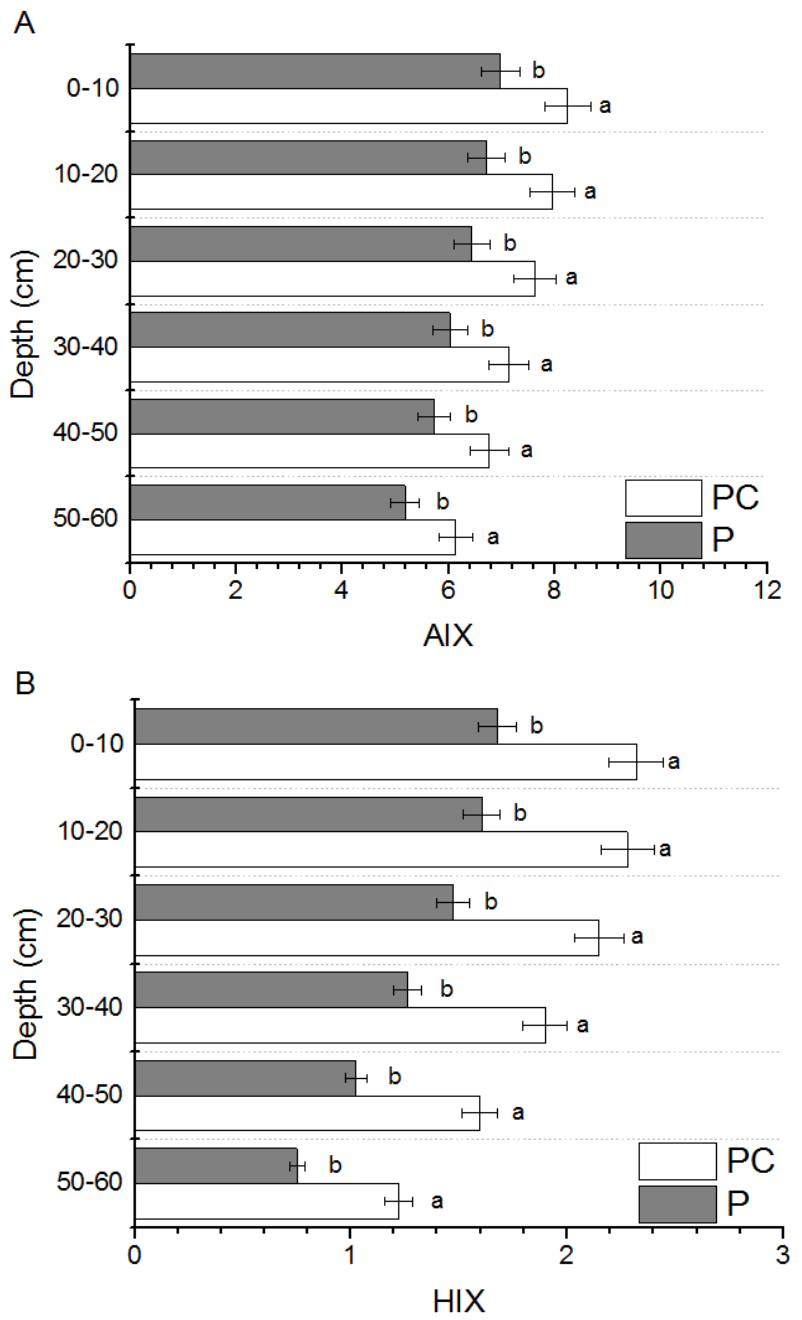

Figure 2. Spectroscopic characteristics of dissolved soil organic matter from the two forest types (mean $\pm \mathrm{SE}, \mathrm{n}=5$ ). Different letters indicate significant differences between the two sites for the same soil layer $(\mathrm{P}<0.05)$. P: pure $P$. massoniana forest; PC: mixed conifer-broadleaf forest of $P$. massoniana and C. carlesii.

Moreover, spectroscopic analyses including AIX and HIX showed similar trends, which tested and verified the outcome of the chemical results. The level of AIX and HIX in soils of PC were much higher than P. In particular, significantly positive relationships were found between DOC, DON and TOC, $\mathrm{TN}$ and $\mathrm{C} / \mathrm{N}$ ratios $(\mathrm{P}<0.05)$. In accordance with our results, soil $\mathrm{DOM}$ characteristics are greatly affected by plant covering (Sitzia et al., 2014, Jiang et al., 2010, Ohno et al., 2014).

\section{CONCLUSION}

Results of the study showed that the characteristics of DOM in forest soils were greatly influenced by different plant covering. Firstly, TOC, TN and $\mathrm{C} / \mathrm{N}$ ratio in soils of $\mathrm{PC}$ were much higher than $\mathrm{P}$, and decreased with soil depths. Secondly, DOC and DON were also much higher in soils of PC than $\mathrm{P}$, together with the spectroscopic analyses results including AIX and HIX.

The empirical approach demonstrated that the forest type have great influence on soil DOM characteristics. The level of DOM in mixed conifer-broadleaf forest (PC) were much higher than pure conifer forest $(\mathrm{P})$. Which suggested that mixed conifer-broadleaf forest was more suitable choice for ecological restoration and reconstruction in southeast China. 


\section{ACKNOWLEDGEMENTS}

We thank Mr. Biao Huang, WeiDong Liu and other members of Jingshan National Forest Farm in Shouning for their assistance during field sampling.

\section{REFERENCES}

[1] Akagi, J., Zsolnay, Á., \& Bastida, F. 2007. Quantity and spectroscopic properties of soil dissolved organic matter (DOM) as a function of soil sample treatments: Air-drying and pre-incubation. Chemosphere, 69(7), 1040-1046.

[2] Batlle-Aguilar, J., Brovelli, A., Luster, J., Shrestha, J., Niklaus, P.A., \& Barry, D.A. 2012. Analysis of carbon and nitrogen dynamics in riparian soils: Model validation and sensitivity to environmental controls. Science of the total environment, 429, 246-256.

[3] Feng, D.L., Huang, X.H. Geng, Y.H. \& Heng, X.Z. 2014. Influence of forest gaps and litter on growth of Cataopsis fargesii and Castanopsis carlesii in the Pinus massoniana pure forest of the Three Gorges Reservoir Area[J]. Applied Mechanics \& Materials, 692, 33-39.

[4] Gangloff, S., Stille, P., Pierret, M.C., Weber, T. \& Chabaux, F. 2014. Characterization and evolution of dissolved organic matter in acidic forest soil and its impact on the mobility of major and trace elements (case of the Strengbach watershed). Geochimica et Cosmochimica Acta, 130, 21-41.

[5] Höll, B. S., Fiedler, S., Jungkunst, H. F., Kalbitz, K., Freibauer, A., Drösler, M. \& Stahr, K. 2009. Characteristics of dissolved organic matter following 20years of peatland restoration. Science of the Total Environment, 408(1), 78-83.

[6] Inamdar, S., Finger, N., Singh, S., Mitchell, M., Levia, D., Bais, H. \& McHale, P. 2012. Dissolved organic matter (DOM) concentration and quality in a forested mid-Atlantic watershed, USA. Biogeochemistry, 108(1-3), 55-76.

[7] Jiang, Y.M., Chen, C.R., Liu, Y.Q. \& Xu, Z.H. 2010. Soil soluble organic carbon and nitrogen pools under mono-and mixed species forest ecosystems in subtropical China. Journal of Soils and Sediments, 10(6), 1071-1081.

[8] Kaiser, K. \& Kalbitz, K. 2012. Cycling downwards-dissolved organic matter in soils. Soil Biology and Biochemistry, 52, 29-32.

[9] Laganiere, J., Paré, D., Bergeron, Y., Chen, H.Y., Brassard, B.W. \& Cavard, X. 2013. Stability of soil carbon stocks varies with forest composition in the Canadian boreal biome. Ecosystems, $16(5), 852-865$.

[10] Lu, R. 1999. Chemistry analysis methods of soil and agriculture. Agricultural Science Publishing House, China, Beijing.

[11] Lyon, B.A., Farré, M.J., De Vera, G.A., Keller, J., Roux, A., Weinberg, H.S. \& Gernjak, W. 2014. Organic matter removal and disinfection byproduct management in South East Queensland's drinking water. Water Science \& Technology: Water Supply, 14(4), 681-689.

[12] Ohno, T., Parr, T.B., Gruselle, M.C.I., Fernandez, I.J., Sleighter, R.L. \& Hatcher, P.G. 2014. Molecular composition and biodegradability of soil organic matter: a case study comparing two New England forest types. Environmental science \& technology, 48(13), 7229-7236.

[13] Sitzia, T, Pizzeghello, D. \& Dainese, M. 2014. Topsoil organic matter properties in contrasted hedgerow vegetation types. Plant and Soil, 383(1-2): 337-348.

[14] Traversa, A., D’Orazio, V. \& Senesi, N. 2008. Properties of dissolved organic matter in forest soils: influence of different plant covering. Forest Ecology and Management, 256(12), 2018-2028. 